\title{
NUTRIENT CONTENT AND ACCEPTABILITY OF SOYBEAN BASED COMPLEMENTARY FOOD
}

\section{Martin $\mathbf{H}^{1}$, Laswai $\mathrm{H}^{* 1}$ and $\mathrm{K}$ Kulwa ${ }^{1}$}

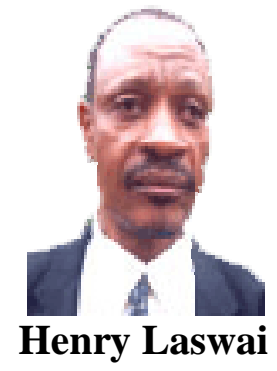

*Corresponding author email: hs2laswai@yahoo.com

${ }^{1}$ Sokoine University of Agriculture, Department of Food Science and Technology, P.O. Box 3006, Chuo Kikuu, Morogoro, Tanzania. 


\begin{abstract}
Cereal gruels, starchy roots and tubers continue to form the bulk of staple foods in the world. Though commercial foods of high quality are available, they are unaffordable by much of the world's population. There is need to develop a different approach to offer families the opportunity to feed their infants improved formulations with traditional staples. A study was carried out in Morogoro region, Tanzania, to determine composition and acceptability of soy-based formulations with banana and cowpeas as traditional staples. Bananas, soybean and cowpeas were prepared and used to make composite flour. Soybean were roasted and milled. Fourteen composite flour formulations were prepared by combining the raw materials in different ratios. Chemical analyses of individual formulations were made to determine their proximate compositions. The ranges of the nutrients in the formulations were: 9.58 to $22.23 \%$ (crude protein), 0.14 to $4.56 \%$ (fibre), 1.15 to $5.51 \%$ (fat) and 67.61 to $81.91 \%$ (carbohydrate). Blending banana with cowpea alone, addition of 10 to $20 \%$ cowpeas in the formulations improved the protein from 9.58 to $13.74 \%$, respectively, but was still lower than the level recommended by Tanzania Bureau of Standards (TBS) and CODEX Alimentarius. Introduction of $10 \%$ soybean instead of cowpeas resulted in improvement of the protein to $17.87 \%$, which was above the recommended level, indicating its superiority as a protein source. Such a level of protein in the formulation was quite encouraging even if there were variations in protein content of soybeans used in the formulations. There were significant differences $(\mathrm{p}<0.05)$ among formulations for appearance, smell, flavour and general acceptability. Consistency of all formulations compared favourably. Complementary foods of good nutritive value can be locally made by using available food ingredients that complement each other in such a way that they meet the nutritional requirement of children. For banana consuming communities, increased consumption of soybean could improve the nutritional status of their children.
\end{abstract}

Key words: Cowpeas, banana, formulations, composition, processing 


\section{INTRODUCTION}

The main nutritional problems in Tanzania and other sub-Saharan African countries are Protein and Energy Deficiencies (PED), Iron Deficiency Anaemia (IDA), Vitamin A Deficiency (VAD) and Iodine Deficiency Disorders (IDD). In Tanzania, PED affects $28 \%$ and IDA $32 \%$ of the general population with children under 5 and pregnant and lactating women being the most susceptible [1]. Major food-related causes of malnutrition include inadequate feeding, foods with low energy and nutrient density, low bioavailability of nutrients, poor access to food, use of poor processing methods and microbial contamination [2]. This situation may be improved by the use of appropriate and sustainable intervention approaches, which include development of low cost, nutritious complementary/ supplementary foods using locally available, underutilized cereals, legumes and oil seeds, and use of affordable bio-enrichment processing techniques such as fermentation of complementary cereals, legumes or oilseed mixtures at the household level [3].

Many of the traditional complementary foods used in developing countries are of low nutrient density. Traditional complementary foods in Tanzania are based on starchy staples, usually cereals such as maize, rice and finger millet and non-cereals such as cassava, sweet potatoes, yams, bananas and plantains [4]. Though commercial foods of high quality are available in markets, they are expensive and a large proportion of the population in Tanzania cannot afford them. Plant protein sources are usually cheaper than animal source protein. It is, therefore, necessary to develop a different approach to offer poor rural and urban women the opportunity to feed their children properly by improving what they already have. FAO/WHO/UNICEF [5] emphasized the use of local foods formulated in the home rather than centrally produced fortified foods for complementary feeding.

Large world production, low cost and desirable nutritional and functional properties of soybean make it a substantial contribution to the world's food protein requirements [1]. Soybean is an abundant and economical source of protein and contains all essential amino acids. Since soybean is a good source of some micronutrients, it can be used to reduce the prevalence of malnutrition in Tanzania. Soy protein is normally used as a supplement in different forms of food for the purpose of improving protein quality. Soy protein is apparently cheaper than animal source protein. Soybean, unlike most oil seed is a dual purpose plant; the bean of the high yielding variety contains about $18 \%$ oil and $38 \%$ protein and the extraction residue represents more than $40 \%$ of the utilization value of the plant [6].

Soybeans can be used in multiple ways, unprocessed and processed. Soybeans can be processed through roasting, fermentation and germination. Unprocessed de-hulled soybeans have an undesirable flavour and bitterness. Moreover, they contain toxic proteins, haemagglutinins and anti-trypsin. These substances must be destroyed or deactivated to make the beans palatable and digestible both for human and animal consumption. Soybean is used for soymilk, soy sauce, tofu (soybean curd), yoghurt, flour and in some beverages [7]. 
In some areas of Tanzania, complementary foods are banana-based. Unfortunately, these bananas are low in protein and therefore unable to meet protein requirements of children. Incorporation of soybeans instead could help increase protein content of complementary foods. This study was, therefore, carried-out to formulate soybeanbased complementary foods and assess their nutrient content and acceptability.

\section{MATERIALS AND METHODS}

Preparation of raw materials: Bananas were peeled, chopped into thin slices and sundried for 3-4 days depending on the intensity of sunlight. Then they were milled to flour by machine. For de-hulling, soybeans were added to boiling water and allowed to boil for 30 minutes. Hot water was removed and cold water added to allow for hand de-hulling. To ferment, pure culture of Rhizopus oligosporous used in tempe production [8] was added, and left to ferment for 36 hours. It was then sun-dried and milled to flour. After de-hulling, soybean was sun-dried, roasted to enhance flavour and milled to flour. Cowpeas, obtained from Morogoro central market, were sorted to remove damaged and extraneous matter, washed, sun-dried and milled to flour. Formulations used in the study are shown in Table 1.

Chemical analyses of the formulations: The proximate composition of the flour formulations was determined according to Official Methods of Analysis [9]. These samples were analyzed for moisture content, ash, crude fibre, crude protein and fat. Carbohydrate content was determined by difference. The analyses were conducted in duplicate. Energy was calculated by using Atwater factors of 4, 4, and 9 for protein, carbohydrate and fat, respectively.

Sensory evaluation: Porridge samples from different formulations were subjected to sensory evaluation using a five point hedonic scale of $1-5$, where $1=$ dislike extremely. 2 = dislike moderately, $3=$ neither like nor dislike, $4=$ like moderately and $5=$ like extremely. Thirty female panellists aged 22 to 45 years were used in this study. The use of adult females instead of children was necessary because of their ability to evaluate objectively the sensory characteristics of the formulations. Porridge prepared consisted of flour and water in the ratio 1:15 and the boiling time was 30 minutes. Data obtained were coded, and subjected to statistical analysis using MSTAT-C to get means, frequency and percentages. Differences among means were compared by Duncan's Multiple Range Test at $\mathrm{p}<0.05$. Variables tested were appearance, smell, taste, consistency, and general acceptability.

\section{RESULTS}

Chemical composition: The results for protein, fat, crude fibre, moisture content, and carbohydrates are summarized in Table 1 . The ranges of nutrient content of all the samples were as follows: crude protein $(9.58-22.23 \%)$ with soybean contributing most to this increase; fibre (0.14-4.56\%); fat (1.15-5.51\%) and ash content $(2.85-5.17 \%)$.

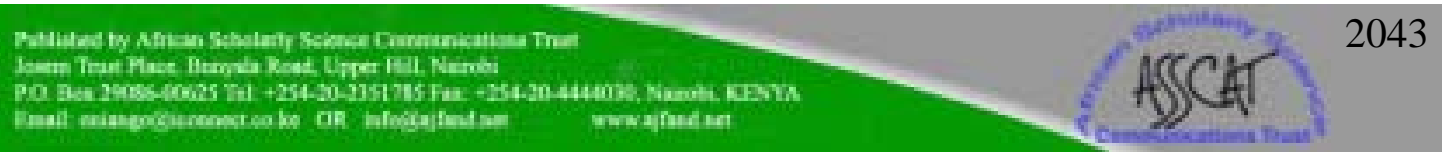


Sensory evaluation: The results of sensory evaluation of thin porridge of different formulation parameters studied are presented in Table 2. Mean scores ranges of attributes evaluated were: Appearance (3.77-4.31), smell (3.76-4.23), taste (3.034.31), consistency (3.77- 4.23) and general acceptability (3.37-4.27). The results of sensory evaluation revealed that there was a significant $(\mathrm{p}<0.05)$ difference in odour (Table 2). The results further showed that the sample with composition Banana: Soybean: Cowpea (80:10:10) was liked by the majority. The least liked was that which contained Banana: Fermented Soybean $=80: 20$. Outcome of sensory evaluation indicated that some porridge samples were similar in appearance while others differed significantly $(\mathrm{p}<0.05)$. The sensory evaluation revealed that there was significant difference $(p<0.05)$ in general acceptability between the samples. Thin porridge of composition B: C: S (80:10:10) ranked high with a mean score of 4.27. However, formulations having high amounts of fermented soybean were not liked.

\section{DISCUSSION}

Chemical composition: The results indicated that, crude protein was highest in the samples which had the largest quantity (20\%) of soybeans. The Tanzania Standards recommend $15.2 \%$ protein while CODEX Alimentarius Standard is 14.95\% [10]. Except for a few samples, most samples had the required amount of crude protein. Formulations with roasted soybean had lower crude protein and this could be attributed to non-enzymatic browning which tends to destroy the nitrogen in the food hence less crude protein [7]. Crude fat in samples containing soybean was high and it increased as the amounts of soybean in formulations were increased. Soybean is important in complementary foods because it adds fat and protein [7], although the amount of crude fat ideally should not exceed $7.5 \%$. Fat contents (1.15 and 5.5\%) in most formulations were within the recommended limits.

Among the three food ingredients used in the formulations, banana contributed much to the carbohydrate content, whereas soybean decreased it. Codex Alimentarius recommends that 100 millilitres of the ready-for-consumption product should provide 60 to $85 \mathrm{kcal}$ when prepared in accordance with the instructions for use [11]. The ash content of the formulations was mainly within the range recommended by Codex Alimentarius. Moisture content of the formulations was mainly above the recommended moisture content for complementary foods by Codex Alimentarius [11], which should not exceed 8\%. The relatively high moisture content in our formulations could therefore, cause storage problems. The samples should be further dried to reduce the moisture content in order to enhance the shelf-life of the food. If the formulation is for immediate use then this would not pose a problem.

Evidence from developing countries shows that adult productivity depends, to a great extent on the contribution of health and nutrition during early childhood. Where adequate nutrients are available, there will be healthy condition that will as a result augment the cognitive brain development of the child and reduce childhood mortality through the child being free from physical and mental retardation, delayed motor development, stunting, neuro-muscular development, speech and hearing disorders,

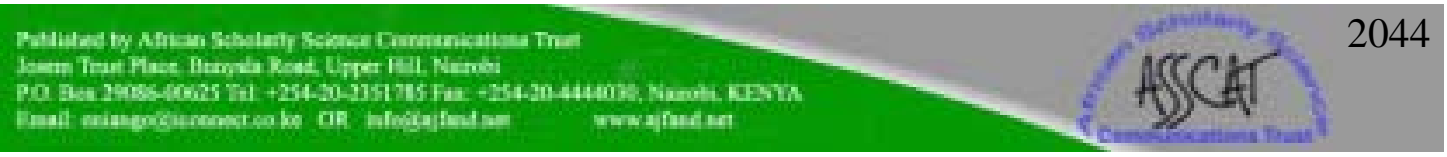


loss of vision and infectious diseases (for example measles and diarrhoea), respiratory diseases (like tuberculosis) and malaria $[12,14]$. To date, none of the sub-regions in sub-Saharan Africa (East and Southern Africa inclusive) meet the recommended daily calorie and protein intakes of 3,000 kcals and $59 \mathrm{~g}$ of protein per capita and these inadequacies are reflected in high infant mortality rates and low birth weight $[12,13$, 15].

Sensory evaluation: Samples with large amounts of cowpea were found to be more appealing than those with high soybean, signalling a fact that soybean inclusion in the formulation negatively influenced product appearance, although not to the extent of making the product unacceptable. Generally, the mean scores of all formulations were accepted (Table 2), showing that judged by this sensory attribute, inclusion of soybean in the formulations at the levels used in this study will not pose problems regarding appearance of the resulting product.

The mean scores for smell were also generally acceptable as seen in Table 2 . However, in comparison with other formulations, Banana-Fermented Soybean formulation was not much preferred perhaps due to the beany flavour of soybean and the smell that resulted from fermentation process as has also been reported in literature by other authors [7].

The mean scores for flavour were generally low, though acceptable to the panellists (Table 2). Usually, soybean is associated with a characteristic beany flavour, which is a limiting factor to acceptability of soybean-based products. As the proportion of soybean was increased in the formulation, there was a decrease in acceptability of the taste. Conversely, untreated soybean and fermented soybean interfered with the taste of the porridge. Formulations with a high amounts of fermented soybean and untreated soybean were least liked judged by this sensory attribute.

All formulations produced food that when cooked in the usual way porridges are cooked did not result in unacceptable consistency (Table 3). The general acceptability also showed that there was no formulation that was generally rejected. However, many of the formulations had generally low mean scores, some marginally above the cut-off score of 3.0 that separated accepted from unaccepted samples. The formulations with highest scores still had soybean in their formulations (for example, B80:C10:RS10; B90:C10; B80: RS9:FS6:C5 and B80:C10:S10, all with mean score above 4.0). This shows that the negative attributes inherent in soybean can still be accommodated in preparation of acceptable soybean-based foods. Soybean has a role to play in achieving good nutrition and health, and efforts need to be made to improve its negative attributes, when it is being introduced in the diets of sub-Saharan Africa, where soybean is a new crop, especially for infants and children.

Legumes have played an important role in the traditional diets of many regions throughout the world. They have traditionally been an important part of the diets of many cultures throughout the world, and they have much to offer. Beans are high in protein, low in saturated fat, and high in complex carbohydrates and fibre. Soybeans

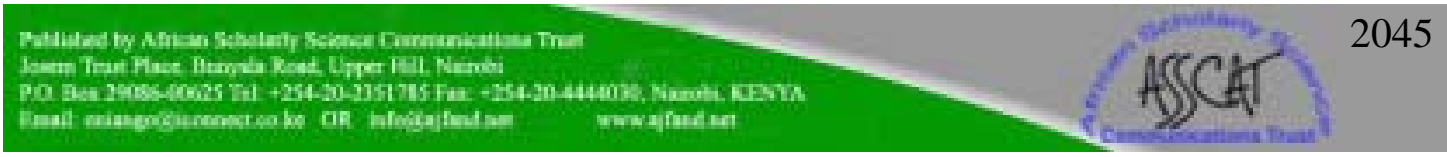


in particular are unique among these legumes because in addition to the mentioned benefits of beans, they are a concentrated source of isoflavones that reduce the risk of cancer, heart disease and osteoporosis. Given the nutrient profile and phytochemical contribution of legumes therefore, nutritionists should make a concerted effort to encourage the public to consume more beans in general and more soy foods in particular [16]. The soybean has the potential to not only meet the nutritional needs of the people, but also put some much needed money in the pockets of farmers and substantially transform their lives. It contains 40 per cent protein, a level much higher than in any other food crop or even livestock. It is made up of 20 per cent oil that other commonly consumed legumes cannot offer, and contains all the eight essential amino acids, making it the healthiest legume crop. Unfortunately, the crop's rich potential is not well exploited in sub-Saharan Africa, where it is mostly seen as a cash crop [17].

The beany flavour that has been cited as cause of low acceptance in soybean-based foods should not pose threats as methods to deal with in bean-based foods like soymilk being flavoured with lemongrass or vanilla or honey have been identified and many of these rely on the use of locally available materials relevant to the type of food in question [18]. Soybean products certainly remain an important objective for developing countries struggling with high levels of undernourishment, in particular the food insecure countries in Africa. It contributes significantly to overall human nutrition in terms of both calorie and protein intake. It can be encouraged in smallholder-based production systems to diversify production, generate income and improve rotation effects that improve productivity of other crops being grown [19]. There is therefore a lot to benefit when soybean is used in infant food formulations.

\section{CONCLUSION}

From the study, it was observed that formulations with high levels of soybean had more protein, ash, fibre and reduced carbohydrate. Generally, the overall acceptability decreased with increasing soybean. The positive attributes of soybeans need to be exploited without compromising the general acceptability. This will in the end contribute to improvement of health and nutrition right from childhood.

\section{RECOMMENDATION}

Introduction of nutrient-rich soybean in food formulation calls for further exploration. The high protein and energy content of soybean needs to be exploited in complementary food formulations.

\section{ACKNOWLEDGEMENT}

The authors are grateful for financial support for this study obtained from SUA (university) PANTIL programme. 
Table 1: Chemical composition of formulations

\begin{tabular}{lcccccccc}
\hline Formulations & \multicolumn{9}{c}{ Chemical composition (\% dry wt) } \\
\cline { 2 - 9 } & Protein & Fibre & Fat & Ash & $\begin{array}{c}\text { Dry } \\
\text { matter }\end{array}$ & $\begin{array}{c}\text { Moisture } \\
\text { content }\end{array}$ & $\begin{array}{c}\text { Carbohy } \\
\text { drate }\end{array}$ & $\begin{array}{c}\text { Energy } \\
\text { content } \\
\text { (Kcal) }\end{array}$ \\
\hline B90:C10* & & & & & & & & \\
B80:C20 & 13.74 & 2.87 & 2.07 & 5.17 & 86.98 & 13.02 & 76.15 & 378.19 \\
B80:C10:S10 & 17.87 & 2.08 & 4.57 & 2.85 & 87.52 & 12.48 & 72.63 & 403.13 \\
B80:C5:S15 & 14.19 & 4.56 & 3.24 & 4.01 & 86.71 & 13.31 & 74.01 & 381.96 \\
B80:S20 & 22.23 & 1.94 & 4.71 & 3.52 & 84.91 & 15.11 & 67.61 & 401.71 \\
B80:C10:S7:RS3 & 14.26 & 2.73 & 2.31 & 4.58 & 86.45 & 13.55 & 76.12 & 382.31 \\
B80:RS20 & 14.74 & 2.35 & 4.76 & 3.97 & 88.22 & 11.78 & 74.18 & 398.52 \\
B80:C10:RS10 & 13.56 & 3.89 & 4.38 & 4.01 & 86.73 & 13.27 & 74.16 & 390.31 \\
B80:C15:FS5 & 12.36 & 0.14 & 3.23 & 4.59 & 86.75 & 13.25 & 79.68 & 397.23 \\
B80:C10:FS10 & 14.93 & 1.33 & 2.96 & 4.56 & 87.72 & 12.28 & 76.22 & 391.24 \\
B80:FS20 & 17.01 & 2.46 & 3.95 & 4.05 & 86.01 & 13.99 & 72.53 & 393.71 \\
B80:RS9:FS6:C5 & 14.21 & 2.78 & 5.51 & 4.01 & 87.32 & 12.68 & 73.51 & 400.38 \\
B80:FS10:RS10 & 15.23 & 2.31 & 3.42 & 4.51 & 87.85 & 12.15 & 74.53 & 389.82 \\
B80:FS15:RS5 & 15.34 & 2.39 & 2.99 & 2.85 & 87.01 & 13.01 & 76.43 & 393.99 \\
\hline
\end{tabular}

*B= Banana, $\mathrm{C}=$ Cowpea, $\mathrm{S}=$ Soybean, $\mathrm{RS}=$ Roasted soybean, $\mathrm{FS}=$ Fermented soybean

Values are the means of duplicate determinations expressed on a dry weight basis.

Table 2: Mean scores of organoleptic evaluation of thin porridge made from different formulations

\begin{tabular}{lccccc}
\hline Formulations & \multicolumn{5}{c}{ Mean scores } \\
\cline { 2 - 6 } & Appearance & Smell & Flavour & Consistency & $\begin{array}{l}\text { General } \\
\text { acceptability }\end{array}$ \\
\hline B90:C10* & $4.17^{\mathrm{ab}}$ & $4.21^{\mathrm{a}}$ & $4.31^{\mathrm{a}}$ & $4.21^{\mathrm{a}}$ & $4.13^{\mathrm{ab}}$ \\
B80:C20 & $4.13^{\mathrm{ab}}$ & $4.01^{\mathrm{bcde}}$ & $3.81^{\mathrm{abcd}}$ & $4.01^{\mathrm{a}}$ & $3.87^{\mathrm{abcd}}$ \\
B80:C10:S10 & $4.01^{\mathrm{ab}}$ & $4.06^{\mathrm{ab}}$ & $3.91^{\mathrm{ab}}$ & $4.07^{\mathrm{a}}$ & $4.01^{\mathrm{abc}}$ \\
B80:C5:S15 & $4.03^{\mathrm{ab}}$ & $3.91^{\mathrm{abc}}$ & $3.71^{\mathrm{bcd}}$ & $3.91^{\mathrm{a}}$ & $3.81^{\mathrm{abcd}}$ \\
B80:S20 & $3.77^{\mathrm{b}}$ & $3.86^{\mathrm{cde}}$ & $3.11^{\mathrm{ef}}$ & $3.87^{\mathrm{a}}$ & $3.37^{\mathrm{d}}$ \\
B80:C10:S7:RS3 & $4.01^{\mathrm{ab}}$ & $3.76^{\mathrm{abc}}$ & $3.71^{\mathrm{bcd}}$ & $3.77^{\mathrm{a}}$ & $3.83^{\mathrm{abcd}}$ \\
B80:RS20 & $3.93^{\mathrm{ab}}$ & $3.83^{\mathrm{de}}$ & $3.43^{\mathrm{cdef}}$ & $3.83^{\mathrm{a}}$ & $3.57^{\mathrm{cd}}$ \\
B80:C10:RS10 & $4.31^{\mathrm{a}}$ & $4.23^{\mathrm{ab}}$ & $4.21^{\mathrm{ab}}$ & $4.23^{\mathrm{a}}$ & $4.27^{\mathrm{a}}$ \\
B80:C15:FS5 & $4.17^{\mathrm{ab}}$ & $3.93^{\mathrm{bcd}}$ & $3.61^{\mathrm{cde}}$ & $3.93^{\mathrm{a}}$ & $3.71^{\mathrm{bcd}}$ \\
B80:C10:FS10 & $4.21^{\mathrm{a}}$ & $3.83^{\mathrm{bcde}}$ & $3.71^{\mathrm{bcd}}$ & $3.83^{\mathrm{a}}$ & $3.83^{\mathrm{abcd}}$ \\
B80:FS20 & $4.11^{\mathrm{ab}}$ & $3.76^{\mathrm{e}}$ & $3.61^{\mathrm{cde}}$ & $3.77^{\mathrm{a}}$ & $3.47^{\mathrm{d}}$ \\
B80:RS9:FS6:C5 & $4.13^{\mathrm{ab}}$ & $4.01^{\mathrm{abc}}$ & $3.93^{\mathrm{abc}}$ & $4.01^{\mathrm{a}}$ & $4.03^{\mathrm{abc}}$ \\
B80:FS10:RS10 & $4.17^{\mathrm{ab}}$ & $3.83^{\mathrm{de}}$ & $3.31^{\mathrm{def}}$ & $3.83^{\mathrm{a}}$ & $3.53^{\mathrm{cd}}$ \\
B80:FS15:RS5 & $3.91^{\mathrm{ab}}$ & $3.83^{\text {cde }}$ & $3.03^{\mathrm{f}}$ & $3.83^{\mathrm{a}}$ & $3.43^{\mathrm{d}}$ \\
\hline
\end{tabular}

*B= Banana, $\mathrm{C}=$ Cowpea, $\mathrm{S}=$ Soybean, $\mathrm{RS}=$ Roasted soybean, $\mathrm{FS}=$ Fermented soybean

Means bearing different superscripts on the same column are significantly different $(\mathrm{p}<0.05)$. 


\section{REFERENCES}

1. Kavishe FP Nutrition: Relevant Actions in Tanzania. Tanzania Food and Nutrition Centre, Monograph Series No.1 pp 20; Tanzania. Tanzania Food and Nutrition Centre, 1993. Dar es Salaam.

2. UNICEF. United Nations Children Fund, Women and children in Tanzania: A Situational analysis. Government printer, Dar es Salaam, 1990.

3. Mugula JK and M Lyimo Evaluation of the nutritional Quality and acceptability of finger millet-based tempe as potential complementary foods in Tanzania. International Journal of Food Science and Nutrition. 1999; 50:275282.

4. Mosha TCE, Laswai HS and I Tetens Nutritional composition and micronutrient status of home made and commercial complementary foods consumed in Tanzania. Plant Foods for Human Nutrition. 2000; 55: 185-205.

5. FAO/WHO/UNICEF. Protein-rich mixtures for complementary foods. Protein Advisory Group of the United Nations, PAG guidelines no. 8 New York, 1971.

6. Collins JL and CR Temalilwa Cassava (Manihote Sculenta Crantz) flour fortification with soyflour. Journal of Food Science. 1981; 46: 1025-1028.

7. Ramamani S, Chandrasekhara HN and MK Narasimba Efficiency of inactivation of trypsin and haemagglutinins by roasting of soybean (Glycine max). Journal of Food Science and Technology. 1996; 33: 197-201.

8. FAO. United Nations Food and Agriculture Organization. Technology of production of edible flours and protein products from soybeans. FAO, agricultural services bulletin No. 97: 1992.

9. AOAC. Official Methods of Analysis. $16^{\text {th }}$ Ed. Association of Official Analytical Chemists, Washington D.C. 1995.

10. FAO/WHO. CODEX Alimentarius Standards for foods for special dietary uses (including foods for infants, and children), joint FAO/WHO food standard program. Codex Alimentarius Commission, 1994: 4, FAO, Rome.

11. CODEX. Standards for follow-up formula. CODEX STAN 156-1987. 1989.

12. Ijaiya GT and AA Yahaya Impact of low nutrient intake on infant mortality rate in sub-Saharan Africa AJFAND 8(4): 405-416.

13. Africa Development Bank (ADB) Gender, Poverty and Environmental Indicators on African Countries. Abidjan ADB, 2003. 
14. Lutter $\mathbf{C}$ Meeting the challenge to improve complementary feeding. SCN News 27: 4-9, 2003.

15. Ouedraogo HZ, Nikiema $\mathbf{L}$, Sakande J, Dramaix-Wilme $\mathbf{M}$ and $\mathbf{P}$ Donnen Home-based practices of complementary foods improvement are associated with better height-for-age Z-score in rural Burkina Faso. AJFAND 8(2): 204218.

16. Messina MJ Legumes and soybeans: overview of their nutritional profiles and health effects. American Journal of Clinical Nutrition, 1999. 70(3): 439S-450S.

17. Anon. Soybean: the golden seed for wealth, health, and soil fertility. [http://knowledge.cta.int/en/Dossiers/Demanding-Innovation/Soilhealth/News/Soybean-the-golden-seed-for-wealth-health-and-soil-fertility] Accessed on 21/01/2010.

18. Laswai HS, Thonya N, Yesaya D, Silayo VCK, Kulwa K, Mpagalile JJ and WRW Ballegu Use of locally available flavouring materials in suppressing the beany taste in soymilk. African Journal of Food, Agriculture, Nutrition and Development. 2009; 9(7): 1548-1560.

19. FAO. The role of soybean in fighting world hunger. pp1-32 [http://www.fao.org/es/esc/common/ecg/125/en/The_role_of_soybeans.pdf]. 